\title{
Management of Stroke Prevention in Canadian Patients with Atrial Fibrillation at Moderate to High Risk of Stroke
}

\author{
William M Semchuk, Brandon Levac, Muria Lara, Annabelle Shakespeare, Thomas Evers, \\ and Jennifer Bolt
}

\begin{abstract}
Background: Many patients with atrial fibrillation who are at moderate to high risk of stroke do not receive anticoagulation with vitamin $\mathrm{K}$ antagonists (VKAs) in accordance with recommendations.

Objective: To determine (1) why Canadian patients with atrial fibrillation who are potentially eligible for VKA do not receive this therapy, (2) why Canadian primary care physicians discontinue VKA therapy, and (3) why VKA therapy is perceived as difficult to manage.

Methods: The study involved a chart review of 3 cohorts of patients with nonvalvular atrial fibrillation at moderate to high risk of stroke: patients who had never received VKA treatment (VKA-naive), those whose treatment had been discontinued, and those whose VKA treatment was considered difficult to manage.
\end{abstract}

Results: Charts for 187 patients (mean age 78.4 years, standard deviation 8.9 years) treated at 39 primary care sites were reviewed (62 treatment-naive, 42 with therapy discontinued, and 83 whose therapy was considered difficult to manage). Atrial fibrillation was paroxysmal in $82(44 \%)$ of the patients, persistent in 47 patients (25\%), and permanent in $58(31 \%)$. One patient in each of the 3 cohorts had experienced a stroke during the 6 months before study participation. Bleeding events were more frequent among patients who had discontinued VKA therapy than in the other 2 groups. Among those whose therapy was discontinued and those whose therapy was difficult to manage, the mean time in the therapeutic range was $46.3 \%$ and $56.4 \%$, respectively. The most common reason for not initiating VKA therapy in treatment-naive patients was the transient nature of atrial fibrillation (25/62 [40\%]). The most common reason for discontinuation of VKA therapy was a bleeding event (10/42 [24\%]). The presence of a concomitant chronic disease was the most common reason that a patient's therapy was considered difficult to manage (46/83 [55\%]).

Conclusions: VKA therapy was not initiated or was discontinued for various reasons. Multiple comorbid conditions made management of VKA therapy more difficult. These findings reflect the challenges that primary care physicians experience in managing the care of patients with atrial fibrillation.

Keywords: atrial fibrillation, stroke, warfarin, management

\section{RÉSUMÉ}

Contexte : De nombreux patients atteints d'une fibrillation auriculaire (FA) et présentant un risque d'accident vasculaire cérébral (AVC) modéré ou élevé ne reçoivent pas d'anticoagulothérapie par un antagoniste de la vitamine $\mathrm{K}$, conformément aux recommandations.

Objectif : Déterminer 1) pourquoi les patients canadiens atteints d'une FA et qui sont des candidats potentiels à l'anticoagulothérapie par un antagoniste de la vitamine $\mathrm{K}$ ne reçoivent pas ce traitement, 2) pourquoi les médecins canadiens de soins primaires interrompent l'anticoagulothérapie par un antagoniste de la vitamine $K$, et 3) pourquoi la prise en charge d'un tel traitement est considérée comme difficile.

Méthodes: Cette étude comportait une analyse des dossiers médicaux des patients de trois cohortes atteints d'une FA non valvulaire et considérés comme présentant un risque modéré ou élevé d'AVC : patients qui n’avaient jamais reçu d'anticoagulothérapie par un antagoniste de la vitamine $\mathrm{K}$, patients chez qui ce traitement avait été interrompu et patients chez qui la prise en charge de ce traitement était considérée comme difficile.

Résultats : Les dossiers médicaux de 187 patients (âge moyen de 78,4 ans, écart-type de 8,9 ans) traités dans 39 établissements de soins primaires ont été analysés (62: jamais traités, 42 : traitement interrompu et 83 : prise en charge considérée comme difficile). On a répertorié $82(44 \%)$ cas de FA paroxystique, $47(25 \%)$ cas de FA persistante et $58(31 \%)$ cas de FA permanente. Un patient dans chacune des trois cohortes a eu un AVC durant les six mois précédant sa participation à cette étude. Les saignements étaient plus fréquents parmi les patients chez qui on avait interrompu le traitement par l'antagoniste de la vitamine K que chez ceux des deux autres groupes. Parmi les patients chez qui le traitement avait été interrompu ou sa prise en charge était considérée comme difficile, le temps moyen dans l'écart thérapeutique était respectivement de 46,3\% et de $56,4 \%$. La raison la plus souvent évoquée pour ne pas instaurer le traitement par un antagoniste de la vitamine $\mathrm{K}$ chez les patients n'ayant jamais reçu un tel traitement était la nature passagère de la FA (25/62 [40 \%]). La raison la plus souvent évoquée pour interrompre ce traitement était les saignements (10/42 [24\%]). La présence d'une comorbidité chronique était la raison la plus souvent évoquée pour expliquer la prise en charge difficile de ce traitement (46/83 [55\%]).

Conclusions : Lanticoagulothérapie par un antagoniste de la vitamine $\mathrm{K}$ n'était pas instaurée ou était interrompue pour diverses raisons. La présence de multiples comorbidités rendait sa prise en charge plus difficile. Ces 
Can J Hosp Pharm. 2013;66(5):296-303 résultats reflètent les difficultés des médecins de soins primaires dans la prise en charge des patients atteints de fibrillation auriculaire.

Mots clés : fibrillation auriculaire, accident vasculaire cérébral, warfarine, prise en charge

[Traduction par l'éditeur]

\section{INTRODUCTION}

A trial fibrillation is the most common cardiac arrhythmia, affecting $1 \%$ to $5 \%$ of the population. ${ }^{1,2}$ The prevalence of this condition is expected to increase dramatically in the next 10 to 20 years because of improved survival of people with coronary artery disease; increasing prevalence of hypertension, heart failure, and diabetes mellitus; and aging of the general population. ${ }^{3-5}$ Atrial fibrillation accounts for $10 \%$ to $15 \%$ of all ischemic strokes and nearly one-quarter of strokes among patients older than 80 years. $^{6}$

Current international guidelines (from the American College of Cardiology, American Heart Association, European Society of Cardiology, and American College of Chest Physicians) recommend anticoagulant therapy (novel oral anticoagulants or vitamin $\mathrm{K}$ antagonists [VKAs]) for patients with atrial fibrillation and moderate to high risk of stroke and antiplatelet therapy for those with low risk of stroke and those for whom anticoagulants are contraindicated. ${ }^{7.8}$ These recommendations have been further refined in the current Canadian guidelines for atrial fibrillation, which suggest oral anticoagulant therapy for patients with a $\mathrm{CHADS}_{2}$ score of 1 or higher ${ }^{9}$ (where $\mathrm{CHADS}_{2}$ is a clinical prediction rule that takes into account congestive heart failure, hypertension, age, diabetes, and prior stroke or transient ischemic attack ${ }^{10}$ ).

The efficacy of agents traditionally available to mitigate stroke risk in patients with atrial fibrillation was highlighted in a 2007 meta-analysis of 29 trials involving a total of 28044 patients. ${ }^{11}$ Compared with control patients, patients receiving adjusted-dose warfarin (6 trials, 2900 participants) had 64\% fewer strokes (95\% confidence interval [CI] $49 \%$ to $74 \%$ ), and patients receiving antiplatelet agents (8 trials, 4876 participants) had 22\% fewer strokes (95\% CI 6\% to 35\%). Warfarin was superior to antiplatelet therapy in 12 trials (12 693 participants), with a relative risk reduction of 39\%, and both therapies were associated with a beneficial trade-off between strokes and major extracranial hemorrhage. ${ }^{11}$ However, the amount of time within the therapeutic range was demonstrated to have a significant effect on whether patients achieved the full benefit of warfarin prophylaxis. ${ }^{12,13}$

Despite the efficacy of warfarin in preventing strokerelated outcomes in patients with atrial fibrillation, it appears that almost half of eligible patients are not receiving this drug. ${ }^{14-17}$ Recently, Gladstone and others, ${ }^{17}$ using data from the
Ontario Stroke Registry, demonstrated a substantial gap between treatment guidelines and the actual treatment of patients admitted to hospital with stroke. Among patients presenting with first ischemic stroke who had known atrial fibrillation, $40 \%$ were receiving warfarin and 30\% were receiving antiplatelet therapy before admission. Among those with a previous history of transient ischemic attack or ischemic stroke, $57 \%$ were taking warfarin before admission. ${ }^{17}$

The challenges associated with using warfarin in patients with atrial fibrillation are important enough that 2 major trials, ACTIVE A and AVERROES, were able to accrue, respectively, 7554 and 5599 patients at moderate to high risk of atrial fibrillation-related stroke for whom physicians thought that warfarin was unsuitable as prophylactic therapy. ${ }^{18,19}$ However, few details were provided in these studies to explain why these patients were deemed unsuitable for VKA therapy.

The purpose of the study reported here was to describe patient and treatment characteristics among those who were potential candidates for anticoagulation on the basis of stroke risk but for whom VKA was not prescribed. The authors also set out to document reasons for not initiating or discontinuing VKA treatment in patients with atrial fibrillation who were at moderate or high risk of stroke and the reasons why some patients' VKA therapy was perceived as difficult to manage.

\section{METHODS}

This retrospective study consisted of a chart review of patients in the practices of Canadian primary care physicians in British Columbia, Ontario, and Quebec. Physicians' practices were selected by random sampling. First, rural and urban areas were distinguished by postal codes and were selected using a Research Randomizer program. Then, using the selected postal codes, a list of registered physicians was searched to identify all active physicians, as defined below. Finally, the required number of physicians (approximately 40) was selected randomly to generate a set of sites to be contacted. To be eligible to participate, primary care physicians were required to have an average weekly case load of more than 100 visits and had to be independently managing their patients' warfarin therapy.

Initially, 1397 physicians were contacted with an invitation to participate; 81 of these expressed interest, and 39 primary care physicians ultimately participated in the study: 14 
from British Columbia, 19 from Ontario, and 6 from Quebec. Physicians' participation in the study was approved by the respective institutional review boards. Each physician received a financial incentive for participation in the study, according to the number of patients included.

Three patient cohorts were studied: VKA-naive (patients who had never received VKA therapy, despite their clinical situation), VKA discontinued (patients previously exposed to VKA, with duration of therapy longer than 3 months and cessation of therapy less than 12 months before inclusion in the study), and VKA therapy deemed "difficult to manage" (patients who had been receiving VKA therapy for more than 3 months at the time of study inclusion but whose therapy was considered difficult to manage, as per the treating physician's criteria). Patients were eligible for the study only if their respective primary care physicians indicated that they had nonvalvular atrial fibrillation on the index date of the study and their warfarin therapy was being actively managed by the participating physician. The index date was the day on which the patient's data were collected. Patients had to be at least 18 years of age, had to be self-administering their medications, and had to be at moderate to high risk of stroke $\left(\mathrm{CHADS}_{2}\right.$ score $\geq 2$ ). Demographic and clinical variables collected were age, sex, height and weight, smoking status, presence of comorbidities and concurrent medications, information pertaining to diagnosis and treatment of atrial fibrillation, antithrombotic medication received, and stroke and bleeding events within the previous 6 months. The VKA treatment regimen and monitoring data for international normalized ratio (INR) were recorded for the previous 12 months or from the date of initiation of VKA treatment.

Patients were excluded if, at the time of study inclusion or as a reason for cessation of therapy, they were pregnant, they had hemorrhagic tendencies or blood dyscrasias, they underwent surgery of the central nervous system or the eye, or they experienced significant trauma leading to surgery. Patients receiving non-VKA anticoagulants such as dabigatran were also excluded.

In Ontario and British Columbia, patient charts were selected by sequential review of patients known to have had atrial fibrillation who were seen during the previous 16 weeks. Physicians were asked to start the review with patients whose family name started with the same letter as the physician's and to follow alphabetical order until sufficient patients were identified; each physician was expected to contribute 5 to 7 patients to the study. In Quebec, where individual informed patient consent was required, an invitation to participate in the study was provided to potentially eligible patients, and they were included in the order in which they presented themselves to their respective physicians' practices. The clinical chart review was performed at each participating site between
February and June 2011 for the entire patient cohort. All study data were collected with a web-based electronic case report form completed by the participating physicians.

Physicians' explanations of the antithrombotic therapeutic approach to patient care were collected as follows: for VKAnaive patients, the reasons why VKA treatment had not been initiated and the use of alternative medication; for patients whose VKA therapy had been discontinued, the reasons for treatment discontinuation and the use of alternative medication; and for patients whose therapy was considered difficult to manage, the length of time and the reason why the patient's therapy had been considered difficult to manage. The length of time that therapy had been considered difficult to manage was assessed by a direct question to the physician. The rationale for not having initiated VKA or for having discontinued VKA and the reason why a patient's therapy was considered difficult to manage were assessed through questions on the case report form with predefined response options and an open response option.

\section{Statistical Analysis}

All results were stratified by study group: patients naive to VKA therapy, patients whose VKA therapy had been discontinued, and patients receiving VKA but whose therapy was considered difficult to manage. Results are presented as number and percentage of patients per response option for categorical variables and as means and standard deviation (SD) for continuous variables. To assess differences among study groups, parametric tests (analysis of variance models) were used for continuous variables and chi-squared tests for categorical variables.

The time within the therapeutic range was calculated on the basis of all INR measurements reported during VKA treatment using the Rosendaal method, ${ }^{20}$ defined as the number of days that the INR value was within the therapeutic range (as defined for each patient) divided by the number of days between consecutive INR measurements. For calculation proposes, INR values were considered to have increased or decreased linearly between 2 consecutive measurements.

Data were analyzed with SAS statistical software, version 9.1 for Windows, and the statistical significance level was set at 0.05 .

\section{RESULTS}

Of the 39 physicians who participated in the study, 29 (74\%) were men. The mean duration of experience with INR monitoring or managing VKA therapy was 19.7 years (SD 9.1 years). Nineteen (49\%) of the physicians were seeing more than 150 patients per week, and only $4(10 \%)$ were seeing fewer than 120 patients per week. 
Table 1. Patients' Sociodemographic and Clinical Characteristics at Study Inclusion

\begin{tabular}{|c|c|c|c|c|c|c|c|c|}
\hline \multirow{4}{*}{$\begin{array}{l}\text { Characteristic } \\
\text { Sex, male } \\
\text { Age (years), mean (SD) }\end{array}$} & \multicolumn{8}{|c|}{ Subgroup; No. (\%) of Patients* } \\
\hline & \multicolumn{2}{|c|}{$\begin{array}{l}\text { VKA Naive } \\
(n=62)\end{array}$} & \multicolumn{2}{|c|}{$\begin{array}{l}\text { VKA Discontinued } \\
\qquad(n=42)\end{array}$} & \multicolumn{2}{|c|}{$\begin{array}{l}\text { VKA Difficult } \\
\text { to Manage } \\
\quad(n=83)\end{array}$} & \multicolumn{2}{|c|}{$\begin{array}{l}\text { Overall } \\
(n=187)\end{array}$} \\
\hline & & (63) & 22 & $(52)$ & 48 & $(58)$ & 109 & $(58)$ \\
\hline & 78.8 & $(10.4)$ & 78.3 & $(9.4)$ & 78.1 & $(7.4)$ & 78.4 & $(8.9)$ \\
\hline \multicolumn{9}{|l|}{ CHADS scoret } \\
\hline $2+2$ & 29 & (47) & 19 & $(45)$ & 36 & $(43)$ & 84 & (45) \\
\hline 3 & 18 & (29) & 13 & (31) & 32 & (39) & 63 & (34) \\
\hline$\geq 4$ & 15 & (24) & 10 & (24) & 15 & (18) & 40 & $(21)$ \\
\hline \multicolumn{9}{|l|}{ Classification of atrial fibrillation } \\
\hline Paroxysmal & 35 & (56) & 18 & (43) & 29 & (35) & 82 & (44) \\
\hline Persistent & 14 & (23) & 11 & (26) & 22 & (26) & 47 & (25) \\
\hline Permanent & 13 & $(21)$ & 13 & (31) & 32 & (39) & 58 & (31) \\
\hline Time since diagnosis (years), mean (SD) & 4.5 & $(7.5)$ & 6.9 & $(8.1)$ & 5.9 & $(5.5)$ & 5.7 & $(6.9)$ \\
\hline Major or minor bleeding event in previous 6 months & 2 & (3) & 7 & $(17)$ & 2 & $(2)$ & 11 & (6) \\
\hline$\geq 3$ HAS-BLED risk factors $\neq$ & & $(50)$ & 17 & $(40)$ & 62 & $(75)$ & 110 & $(59)$ \\
\hline Time in therapeutic range (\%), mean (SD) & \multicolumn{2}{|c|}{ NA } & \multicolumn{2}{|c|}{$46.3(27.4)$} & \multicolumn{2}{|c|}{$56.4(26.9)$} & \multicolumn{2}{|c|}{ NA } \\
\hline Interval between INR measurements (days), mean (SD) & \multicolumn{2}{|c|}{ NA } & \multicolumn{2}{|c|}{$26.1(29.6)$} & \multicolumn{2}{|c|}{$21.1(22.7)$} & \multicolumn{2}{|c|}{ NA } \\
\hline \multicolumn{9}{|c|}{$\begin{array}{l}\text { INR = international normalized ratio, NA = not applicable, SD = standard deviation, VKA = vitamin K antagonist. } \\
\text { *Except where indicated otherwise. } \\
\text { †CHADS is a clinical prediction rule taking into account congestive heart failure, hypertension, age, diabetes mellitus, and prior stroke } \\
\text { fHAS-BLED is a clinical prediction rule taking into account hypertension, renal disease, liver disease, previous stroke, previous } \\
\text { or predisposition to bleeding, labile INR, age, medications, and alcohol use. }\end{array}$} \\
\hline
\end{tabular}

A total of 187 patients were included in the study: 62 VKA-naive, 42 with VKA treatment discontinued, and 83 whose therapy was considered difficult to manage. The maximum number of patients included per physician was 15 (mean 4.8 patients, SD 3.2 patients). The mean age of the study population was 78.4 years, and $109(58 \%)$ of the participants were men (Table 1). Fewer than half (84 [45\%]) had a CHADS score of 2, and the remainder (103 [55\%]) had a $\mathrm{CHADS}_{2}$ score of 3 or greater. Paroxysmal atrial fibrillation was the most common form of atrial fibrillation (82 [44\%]); the persistent and permanent forms were less frequent $(25 \%$ and $31 \%$, respectively). The mean time since diagnosis was approximately 6 years, although differences across groups were observed $(p<0.001)$, with more recent diagnosis for VKAnaive patients ( 4.53 years) than for those whose therapy was considered difficult to manage (5.94 years); patients whose VKA therapy had been discontinued had the longest history of atrial fibrillation (6.92 years). Among patients with previous or current VKA therapy, the mean time in the therapeutic range was $46.3 \%$ (SD 27.4\%) and 56.4\% (SD 26.9\%), respectively. The mean number of days between INR measurements was 26.1 (SD 29.6) for patients whose VKA therapy had been discontinued (for INR values measured while they were still taking VKAs) and 21.1 (SD 22.7) for those whose therapy was considered difficult to manage.

Levels of comorbidity at the index date were similar across the 3 groups, with at least one concurrent condition being reported for $87 \%$ (54/62) of VKA-naive patients, 90\% (38/42) of those with VKA discontinued, and $92 \%(76 / 83)$ of those whose therapy was difficult to manage (Table 2). The comorbidities were mainly cardiovascular, followed closely by respiratory (Table 2). The population was at high risk of bleeding, with more than half of the patients (110 [59\%]) having 3 or more HAS-BLED risk factors (see Table 1) (where HAS-BLED is a clinical rule that accounts for hypertension, renal disease, liver disease, previous stroke, previous or predisposition to bleeding, labile INR, age, medications, and alcohol use). The highest rate of minor and major bleeding events (combined) in the previous 6 months was seen among those who had discontinued VKA therapy (8 events in a total of 7 patients [17\% of the sample]) and was heavily weighted to major bleeding events. The VKA-naive group and those whose therapy was considered difficult to manage had 2 bleeding events each (3\% and $2 \%$ of the sample, respectively).

The most common reason that physicians gave for not initiating VKA for VKA-naive patients was the transient nature of atrial fibrillation (40\% [25/62]). For patients in whom VKA had been discontinued, the main reason for treatment discontinuation was a bleeding event (24\% [10/42]) (Table 3). Among patients whose VKA therapy was considered difficult to manage, the most common reason cited for this assessment was concomitant chronic disease (55\% [46/83]), closely followed by poor INR control (54\% [45/83]). In this group, the mean time since VKA therapy was deemed under poor control was 31.9 months (SD 42.2 months) (approximately 2.7 years [SD 3.5 years $])$. 
Table 2. Comorbidities and Other Clinical Characteristics at Index Date

\begin{tabular}{|c|c|c|c|c|c|c|c|c|}
\hline \multirow{3}{*}{ Comorbidities at index date† } & \multicolumn{8}{|c|}{ Subgroup; No. (\%) of Patients* } \\
\hline & \multicolumn{2}{|c|}{$\begin{array}{l}\text { VKA Naive } \\
(n=62)\end{array}$} & \multicolumn{2}{|c|}{$\begin{array}{l}\text { VKA Discontinued } \\
\qquad(n=42)\end{array}$} & \multicolumn{2}{|c|}{$\begin{array}{l}\text { VKA Difficult } \\
\text { to Manage } \\
\quad(n=83)\end{array}$} & \multicolumn{2}{|c|}{$\begin{array}{c}\text { Overall } \\
(n=187)\end{array}$} \\
\hline & & & & & & & & \\
\hline No. of patients with $\geq 1$ comorbidities & 54 & $(87)$ & 38 & $(90)$ & 76 & $(92)$ & 168 & $(90)$ \\
\hline Cardiovascular disease & 37 & (60) & 30 & (71) & 58 & (70) & 125 & (67) \\
\hline Chronic pulmonary disease & 15 & (24) & 16 & (38) & 18 & $(22)$ & 49 & (26) \\
\hline Non-insulin-dependent diabetes mellitus & 0 & (0) & 0 & (0) & 1 & (1) & 1 & (1) \\
\hline Risk factors & 59 & (95) & 35 & $(83)$ & 74 & (89) & 168 & (90) \\
\hline Hypertension & 24 & (39) & 12 & (29) & 23 & $(28)$ & 59 & (32) \\
\hline Abnormal liver function & 1 & $(2)$ & 3 & (7) & 0 & (0) & 4 & (2) \\
\hline Abnormal renal function & 4 & (6) & 3 & (7) & 5 & (6) & 12 & (6) \\
\hline Stroke history & 17 & $(27)$ & 14 & (33) & 23 & $(28)$ & 54 & (29) \\
\hline Bleeding history & 5 & (8) & 8 & (19) & 5 & (6) & 18 & (10) \\
\hline \multicolumn{9}{|l|}{ Elderly } \\
\hline Treatment with drug(s) that promote bleeding§॥ & 47 & (76) & 21 & $(50)$ & 61 & $(73)$ & 129 & (69) \\
\hline Excess alcohol useी & 5 & (8) & 4 & (10) & 0 & $(0)$ & 9 & (5) \\
\hline \multicolumn{9}{|l|}{ Prior bleeding event** } \\
\hline No. of patients & 2 & (3) & 7 & $(17)$ & 2 & $(2)$ & 11 & (6) \\
\hline Minor & 0 & & 2 & & 1 & & 3 & $(25)$ \\
\hline Genitourinary & 0 & & 0 & & 1 & & 1 & (33) \\
\hline Hemothorax & 0 & & 1 & & 0 & & 1 & (33) \\
\hline Nasal & 0 & & 1 & & 0 & & 1 & (33) \\
\hline Major & 2 & & 6 & & 1 & & 9 & (75) \\
\hline Gastrointestinal & 0 & & 2 & & 1 & & 3 & (33) \\
\hline Intracranial & 1 & & 2 & & 0 & & 3 & (33) \\
\hline Fall in hemoglobin level $\geq 20 \mathrm{~g} / \mathrm{L}$ & 1 & & 1 & & 0 & & 2 & $(22)$ \\
\hline Leading to transfusion of $\geq 2$ units whole blood & & & & & & & & \\
\hline or red cells & 0 & & 1 & & \multicolumn{2}{|l|}{0} & 1 & (11) \\
\hline $\begin{array}{l}\text { Time since last minor bleeding event (months), } \\
\text { mean (SD) }\end{array}$ & \multicolumn{2}{|c|}{ NA } & \multicolumn{2}{|c|}{$0.43(0.19)$} & 2.30 & NA & 1.05 & 1.09) \\
\hline $\begin{array}{l}\text { Time since last major bleeding event (months), } \\
\text { mean (SD) }\end{array}$ & 3.80 & $0.79)$ & 2.35 & 2.21) & 0.39 & NA & 2.47 & 2.00) \\
\hline
\end{tabular}

$\mathrm{NA}=$ not applicable, SD = standard deviation, VKA = vitamin $\mathrm{K}$ antagonist.

*Except where indicated otherwise.

†Multiresponse question: patients could have more than one comorbidity or bleeding event.

$\neq$ Age $>65$ years.

$\S$ Antiplatelet agents or nonsteroidal anti-inflammatory drugs.

$\| p=0.010$.

П $p=0.021$

**Percentages were not calculated for type of bleeding within subgroups. One of the patients in the "VKA discontinued" group had both a major and a minor bleeding event. In last column, percentages of minor and major bleeding events were calculated in relation to the total number of bleeding events $(n=12)$; percentages of each type of event (e.g., genitourinary or hemothorax) were calculated in relation to total number of minor events $(n=3)$ or total number of major events $(n=9)$.

\section{DISCUSSION}

The population represented by this cohort of patients reflects the challenging scenarios that Canadian primary care physicians encounter when attempting to reduce the risk of stroke in patients with atrial fibrillation who are at moderate to high risk of an event. These patients often suffer from a number of comorbidities, and as their $\mathrm{CHADS}_{2}$ score increases, so generally does their bleeding risk, as indicated by the HAS-BLED score. Indeed, in this cohort, more than half of the patients were at high risk of a bleeding event, as indicated by a HAS-BLED score of 3 or greater.
Among patients who were at moderate to high risk of stroke but who were not receiving VKA therapy, the most common reason cited for not initiating such therapy $(40 \%$ of patients) was the transient nature of atrial fibrillation. Interpreting this information is challenging, as atrial fibrillation is considered to be recurrent if a patient experiences 2 or more episodes. However, one of the initial inclusion criteria for this study was a diagnosis of nonvalvular atrial fibrillation. Although a minimum 2 bouts of atrial fibrillation was not required to support this diagnosis, it was made clear to the participating physicians that patients had to have a valid 
Table 3. Most Common Reasons Cited by Physicians for Not Initiating VKA Treatment, Discontinuing VKA Treatment, or Considering VKA Treatment Difficult to Manage

\begin{tabular}{|c|c|c|c|c|c|c|}
\hline Reason Cited & $\begin{array}{r}\text { VKA } \\
(n=62\end{array}$ & $\begin{array}{l}\text { Naive } \\
\text { atients)* }\end{array}$ & $\begin{array}{c}\text { VKA Dis } \\
(n=42\end{array}$ & $\begin{array}{l}\text { ontinued } \\
\text { satients) }\end{array}$ & $\begin{array}{r}\text { VKA Di } \\
\text { Man } \\
\text { (n= } 83\end{array}$ & $\begin{array}{l}\text { ficult to } \\
\text { age* } \\
\text { atients) }\end{array}$ \\
\hline Transient nature of atrial fibrillation & 25 & $(40)$ & 0 & & 0 & \\
\hline Monitoring or adherence concerns with VKA & 17 & $(27)$ & 8 & $(19)$ & 29 & (35) \\
\hline Patient indicated difficulty in following lifestyle advice & 0 & & 0 & & 25 & (30) \\
\hline Risk of bleeding & 14 & $(23)$ & 0 & & 0 & \\
\hline Bleeding event & 0 & & 10 & $(24)$ & 0 & \\
\hline Clinical event (e.g., fall or surgery) & 0 & & 5 & $(12)$ & 0 & \\
\hline Risk of fall & 19 & (31) & 0 & & 0 & \\
\hline Low risk of stroke & 11 & (18) & 0 & & 0 & \\
\hline Poor INR control & 0 & & 3 & $(7)$ & 45 & $(54)$ \\
\hline Increased INR monitoring frequency & 0 & & 0 & & 33 & $(40)$ \\
\hline Concomitant chronic diseases & 0 & & 0 & & 46 & $(55)$ \\
\hline Use of concomitant medications & 0 & & 0 & & 28 & (34) \\
\hline $\begin{array}{l}\text { Change in atrial fibrillation status (e.g., successful } \\
\text { cardioversion) }\end{array}$ & 0 & & 6 & $(14)$ & 0 & \\
\hline Patient’s decision & 0 & & 7 & $(17)$ & 0 & \\
\hline Already receiving antiplatelet therapy & 7 & $(11)$ & 0 & & 0 & \\
\hline
\end{tabular}

INR = international normalized ratio, VKA = vitamin $\mathrm{K}$ antagonist.

*For some patients, the physician cited more than one reason. Note that this table reports physicians' stated reasons for not initiating or for discontinuing VKA therapy or for considering VKA therapy difficult to manage, which may be subject to recall bias; in contrast, Tables 1 and 2 report clinical data as recorded in the patients' charts.

diagnosis of atrial fibrillation to be entered into the study. Previous data support the use of VKA therapy for at-risk patients, regardless of the type of atrial fibrillation (paroxysmal, persistent, or permanent) that is present. Hart and others ${ }^{21}$ analyzed stroke risk in patients with intermittent atrial fibrillation using data from a longitudinal cohort study that compared 460 participants with intermittent atrial fibrillation and 1552 with sustained (permanent) atrial fibrillation treated with acetylsalicylic acid in the Stroke Prevention in Atrial Fibrillation studies and followed for a mean of 2 years. In that large cohort, analysis by risk category (based on $\mathrm{CHADS}_{2}$ score) showed that patients with intermittent atrial fibrillation had stroke rates similar to rates among patients with sustained (permanent) atrial fibrillation and similar risk factors for stroke. ${ }^{21}$ Data from the observational Euro Heart Survey, published by Nieuwlaat and others, ${ }^{22}$ demonstrated that the incidence of stroke was comparable among atrial fibrillation subtypes.

The second most common reason for not starting VKA therapy was a concern that patients had a high risk of falling (Table 3). Fall risk does not necessarily preclude VKA therapy and must be evaluated within the context of potential VKA benefit. Gage and others ${ }^{23}$ quantified the incidence of intracranial hemorrhage among 1245 Medicare beneficiaries with atrial fibrillation who were at high fall risk relative to a cohort not at high fall risk. The patients were elderly (mean 80 years), and $48 \%$ had received a prescription for warfarin at hospital discharge. The rates of intracranial hemorrhage per 100 patient-years were 2.8 (95\% confidence interval [CI] 1.9-4.1) among patients at high risk for falls and 1.1 (95\% CI 1.0-1.3) among other patients $(p<0.0001)$. Rates of traumatic intracranial hemorrhage were 2.0 (95\% CI 1.3-3.1) among patients at high risk for falls and 0.34 (95\% CI 0.27-0.45) among other patients $(p<0.0001)$. Patients with atrial fibrillation who were at high risk for falls were also at substantially increased risk of intracranial hemorrhage, especially traumatic intracranial hemorrhage. However, because of their high stroke risk (based on the $\mathrm{CHADS}_{2}$ score), the benefit from anticoagulant therapy appeared to outweigh the risk from VKA-based stroke prophylaxis and the subsequent risk of falls and intracranial hemorrhage. ${ }^{23}$ More recently, Donzé and others ${ }^{24}$ assessed the relationship between high fall risk and major bleeding in 515 patients taking oral anticoagulants (64\% men, mean age 71.2 years). In that cohort, fall risk was assessed with 2 validated questions: (1) Did you fall during the last year? (2) If not, did you notice any problems with gait, balance, or mobility? More than half of the cohort was found to be at high fall risk, and at 1 year $7 \%$ had suffered a major bleeding event. Patients at high fall risk had more bleeding events than those at low risk (8 versus 6.8 per 100 patient-years, respectively), although the difference was not statistically significant. In 3 patients, major bleeding (nonfatal subdural hemorrhage) occurred immediately after a fall. ${ }^{24}$

In the current study, the primary reason for discontinuing VKA therapy was a recent bleeding event. Almost one-quarter (24\%) of the patients in this group had suffered a bleeding event before warfarin was stopped, and the majority of these 
were considered major. Other reasons that physicians chose to discontinue warfarin in this group were the difficulty that patients had in adhering to the VKA regimen (including obtaining INR measurements) and patients' decisions (which may also reflect adherence issues). Data pertaining to adherence to warfarin therapy are limited. The IN-RANGE study, which involved 136 patients from 3 anticoagulation clinics, demonstrated that patients had substantial difficulty maintaining adherence to warfarin regimens and that poor adherence had a significant effect on anticoagulation control..$^{25}$ Indeed, in the study reported here, the time within the therapeutic range was substantially lower for patients whose therapy was discontinued (46.3\%) than for those whose therapy was difficult to manage (56.4\%), for whom patient-related issues were the fourth and sixth most common reasons for considering warfarin therapy difficult to manage. In the Euro Heart Survey, only about 35\% of patients remained on VKAs for 5 years. ${ }^{26}$

Cruess and others ${ }^{27}$ sought to explain the association between attitudinal and behavioural factors related to nonadherence to warfarin medication regimens. A number of treatment prognostic scales (Interventional Fragility, Medication Abuse, Information Discomfort, and Utilization Excess), as well as social isolation, were associated with warfarin nonadherence. Patients acknowledging a greater sensitivity to illness-related information from physicians and lack of receptivity to details regarding their medical illness seemed to be at greater risk for warfarin nonadherence. ${ }^{27}$

Physicians indicated that concomitant disease, poor INR control, and frequency of monitoring were concerns causing them to classify VKR therapy as difficult to manage. Surprisingly, though, the mean time within the therapeutic range in this cohort $(56.4 \%$, albeit with a wide standard deviation [26.9\%]) was as good as or better than what the literature suggests is generally obtained. Bungard and other ${ }^{28}$ found that only $36.5 \%$ of patients with nonvalvular atrial fibrillation admitted to a Canadian hospital had therapeutic INR upon admission. Matchar and others ${ }^{29}$ found that time within the therapeutic range ranged from $47.7 \%$ to $55.6 \%$ in 6 large managed care organizations in the United States. These rates were slightly lower than those published by Kalra and others, ${ }^{30}$ who demonstrated that INR within the therapeutic range was achieved $61 \%$ of the time in patients with chronic nonvalvular atrial fibrillation from general medical clinics in a district general hospital.

The availability of the novel oral anticoagulants (dabigatran, rivaroxaban, and apixaban) for stroke prophylaxis in patients with atrial fibrillation may offer an advantage over VKA with respect to some of the care gaps identified in this study. With lower rates of major and intracranial hemorrhage, lack of therapeutic drug monitoring, standard dosing regimens, and minimal drug-drug, drug-disease, and drug-diet interactions, these agents may be reasonable therapeutic alternatives. ${ }^{31-33}$ However, caveats pertaining to financial coverage, limited experience with these agents in diverse populations and patients with multiple comorbidities, and lack of a reversal agent may result in continuing challenges for both patients and clinicians.

This study had several limitations. The sample size was limited, with 187 patients from 3 provinces. As well, the number of patients varied among physicians' practices and among provinces. It is likely that the physicians who agreed to participate in this trial had a higher level of interest in the subject than those who did not, and as such may have had more knowledge and consequently taken better care of their patients. One finding of concern was the lack of use of warfarin for patients with "transient atrial fibrillation". The validity of this finding may be questionable, given that we did not require 2 documented episodes of atrial fibrillation to validate the diagnosis. Finally this retrospective chart analysis was fraught with all of the inherent limitations of this study design.

\section{CONCLUSIONS}

This study demonstrated that physicians face numerous challenges in utilizing VKA therapy for patients with atrial fibrillation. These challenges include the transient nature of atrial fibrillation and the narrow therapeutic margin of warfarin, as well as the challenges that patients experience in remaining adherent with warfarin therapy and the monitoring required.

\section{References}

1. Feinberg WM, Blackshear JL, Laupacis A, Kronmal R, Hart RG. Prevalence, age distribution, and gender of patients with atrial fibrillation. Analysis and implications. Arch Intern Med. 1995;155(5):469-73.

2. de Lusignan S, Van vlymen J, Hague N, Thana L, Dzregah B, Chan T. Preventing stroke in people with atrial fibrillation: a cross-sectional study. J Public Health (Oxf). 2005;27(1):85-92.

3. Valderrama AL, Dunbar SB, Mensah GA. Atrial fibrillation: public health implications. Am J Prev Med. 2005;29(5 Suppl 1):75-80.

4. Savelieva I, Camm J. Update on atrial fibrillation: part I. Clin Cardiol. 2008:31(2):55-62.

5. Savelieva I, Camm J. Update on atrial fibrillation: part II. Clin Cardiol. 2008;31(3):102-8.

6. Wolf PA, Abbot RD, Kannel WB. Atrial fibrillation as an independent risk factor for stroke: the Framingham Study. Stroke. 1991;22(8):983-8.

7. Fuster V, Rydén LE, Cannom DS, Crijns HJ, Curtis AB, Ellenbogen KA, et al. ACC/AHA/ESC 2006 guidelines for the management of patients with atrial fibrillation. Executive summary: a report of the American College of Cardiology/American Heart Association Task Force on Practice Guidelines and the European Society of Cardiology Committee for Practice Guidelines (Writing Committee to Revise the 2001 Guidelines for the Management of Patients With Atrial Fibrillation). Eur Heart J. 2006;27(16):1979-2030. Erratum in: Eur Heart J. 2007;28(16):2046.

8. Singer DE, Albers GW, Dalen JE, Fang MC, Go AS, Halperin JL, et al. Antithrombotic therapy in atrial fibrillation. American College of Chest Physicians evidence-based clinical practice guidelines (8th edition). Chest. 2008;133(6 Suppl):546S-592S.

9. Cairns J, Connolly S, McMurtry S, Stephenson M, Talajic M; CCS Atrial Fibrillation Guidelines Committee. Canadian Cardiovascular Society atrial fibrillation guidelines 2010: prevention of stroke and systemic thromboembolism in atrial fibrillation and flutter. Can J Cardiol. 2011;27(1):74-90. 
10. Gage BF, Waterman AD, Shannon W, Boechler M, Rich MW, Radford MJ. Validation of clinical classification schemes for predicting stroke: results from the National Registry of Atrial Fibrillation. JAMA. 2001;285(22):2864-70.

11. Hart RG, Pearce LA, Aguilar MI. Meta-analysis: antithrombotic therapy to prevent stroke in patients who have nonvalvular atrial fibrillation. Ann Intern Med. 2007;146(12):857-67.

12. White HD, Gruber M, Feyzi J, Kaatz S, Tse HF, Husted S, et al. Comparison of outcomes among patients randomized to warfarin therapy according to anticoagulant control: results from SPORTIF III and V. Arch Intern Med. 2007;167(3):239-45.

13. Hylek E, Go AS, Chang Y, Jensvold NG, Henault LE, Selby JV, et al. Effect of intensity of oral anticoagulation on stroke severity and mortality in atrial fibrillation. N Engl J Med. 2003;349(11):1019-26.

14. Walker AM, Bennett D. Epidemiology and outcomes in patients with atrial fibrillation in the United States. Heart Rhythm. 2008;5(10): 1365-72.

15. Fang MC, Stafford RS, Ruskin JN, Singer DE. National trends in antiarrhythmic and antithrombotic medication use in atrial fibrillation. Arch Intern Med. 2004;164(1):55-60.

16. Dinh T, Nieuwlaat R, Tieleman RG, Büller HR, van Charante NA, Prins $\mathrm{MH}$, et al. Antithrombotic drug prescription in atrial fibrillation and its rationale among general practitioners, internists and cardiologists in The Netherlands-the EXAMINE-AF study. A questionnaire survey. Int J Clin Pract. 2007;61(1):24-31.

17. Gladstone DJ, Bui E, Fang J, Laupacis A, Lindsay MP, Tu JV, et al. Potentially preventable strokes in high-risk patients with atrial fibrillation who are not adequately anticoagulated. Stroke. 2009;40(1):235-40.

18. ACTIVE Investigators; Connolly SJ, Pogue J, Hart RG, Hohnloser SH, Pfeffer M, Chrolavicius S, et al. Effect of clopidogrel added to aspirin in patients with atrial fibrillation. N Engl J Med. 2009;360(20):2066-78.

19. Connolly SJ, Eikelboom J, Joyner C, Diener HC, Hart R, Golitsyn S, et al.; AVERROES Steering Committee and Investigators. Apixaban in patients with atrial fibrillation. $N$ Engl J Med. 2011;364(9):806-17.

20. Rosendaal FR, Cannegieter SC, van der Meer FJ, Briët E. A method to determine the optimal intensity of oral anticoagulant therapy. Thromb Haemost. 1993;69(3):236-9.

21. Hart RG, Pearce LA, Rothbart RM, McAnulty JH, Asinger RW, Halperin JL; Stroke Prevention in Atrial Fibrillation Investigators. Stroke with intermittent atrial fibrillation: incidence and predictors during aspirin therapy. J Am Coll Cardiol. 2000;35(1):183-7.

22. Nieuwlaat R, Dinh T, Olsson SB, Camm AJ, Capucci A, Tieleman RG, et al.; Euro Heart Survey Investigators. Should we abandon the common practice of withholding oral anticoagulation in paroxysmal atrial fibrillation? Eur Heart J. 2008;29(7):915-22.

23. Gage BF, Birman-Deych E, Kerzner R, Radford MJ, Nilasena DS, Rich MW. Incidence of intracranial hemorrhage in patients with atrial fibrillation who are prone to fall. Am J Med. 2005;118(6):612-7.

24. Donzé J, Clair C, Hug B, Rodondi N, Waeber G, Cornuz J, et al. Risk of falls and major bleeds in patients on oral anticoagulation therapy. $A m \mathrm{~J}$ Med. 2012;125(8):773-8.

25. Kimmel S, Chen Z, Price M, Parker CS, Metlay JP, Christie JD, et al. The influence of patient adherence on anticoagulation control with warfarin: results from the International Normalized Ratio Adherence and Genetics (IN-RANGE) Study. Arch Intern Med. 2007;167(3):229-35.

26. Nieuwlaat R, Olsson SB, Lip GY, Camm AJ, Breithardt G, Capucci A, et al.; Euro Heart Survey Investigators. Guideline-adherent antithrombotic treatment is associated with improved outcomes compared with undertreatment in high-risk patients with atrial fibrillation. The Euro Heart Survey on Atrial Fibrillation. Am Heart J. 2007;153(6):1006-12.
27. Cruess DG, Localio AR, Platt AB, Brensinger CM, Christie JD, Gross R, et al. Patient attitudinal and behavioral factors associated with warfarin non-adherence at outpatient anticoagulation clinics. Int J Behav Med. 2010;17(1):33-42.

28. Bungard TJ, Ackman ML, Ho G, Tsuyuki RT. Adequacy of anticoagulation in patients with atrial fibrillation coming to a hospital. Pharmacotherapy. 2000;20(9):1060-5.

29. Matchar DB, Samsa GP, Cohen SJ, Oddone EZ, Jurgelski AE. Improving the quality of anticoagulation of patients with atrial fibrillation in managed care organizations: results of the managing anticoagulation services trial. Am J Med. 2002;113(1):42-51.

30. Kalra L, Yu G, Perez I, Lakhani A, Donaldson N. Prospective cohort study to determine if trial efficacy of anticoagulation for stroke prevention in atrial fibrillation translates into clinical effectiveness. BMJ. 2000; 320(7244):1236-9.

31. Connolly SJ, Ezekowitz MD, Yusuf S, Eikelboom J, Oldgren J, Parekh A, et al.; RE-LY Steering Committee and Investigators. Dabigatran versus warfarin in patients with atrial fibrillation. $N$ Engl J Med. 2009; 361(12):1139-51.

32. Patel MR, Mahaffey KW, Garg J, Pan G, Singer DE, Hacke W, et al; ROCKET AF Investigators. Rivaroxaban versus warfarin for nonvalvular atrial fibrillation. N Engl J Med. 2011;365(10):883-91.

33. Granger CB, Alexander JH, McMurray JJ, Lopes RD, Hylek EM, Hanna $\mathrm{M}$, et al.; ARISTOTLE Committees and Investigators. Apixaban versus warfarin in patients with atrial fibrillation. $N$ Engl J Med. 2011; 365(11):981-92.

William M Semchuk, MSc, PharmD, is with Pharmacy Practice in the Regina Qu'Appelle Health Region, Regina, Saskatchewan.

Brandon Levac, MSc, MBA, is with Government Affairs, Bayer Inc, Toronto, Ontario.

Muria Lara, MD, MSc, is with the Research department, IMS Health, Barcelona, Catalonia, Spain.

Annabelle Shakespeare, MSc, is with the Research department, Bayer plc, Uxbridge, Middlesex, United Kingdom.

Thomas Evers, MSc, PhD, is with the Statistics department, Bayer Pharma AG, Wuppertal, Milongys, Germany.

Jennifer Bolt, PharmD, is with the Pharmacy, Regina Qu'Appelle Health Region, Regina, Saskatchewan.

Competing interests: William Semchuk attended and chaired a consultancy meeting for Bayer (for a topic outside the scope of this article); was paid by Bayer to present symposia and lectures on atrial fibrillation; and received a grant from Bayer to attend a conference in 2010. Brandon Levac owns stock and/or stock options through Bayer (as an employee of the company). None declared for Muria Lara, Annabelle Shakespeare, Thomas Evers, and Jennifer Bolt.

Address correspondence to:
Dr William M Semchuk
Pharmacy Practice
Regina Qu'Appelle Health Region
1440 14th Avenue
Regina SK S4P OW5
e-mail: bill.semchuk@rqhealth.ca

